\title{
Energy Consumption Evaluation and Optimization of Radiant and Personalized Cooling in Hot-Humid and Dry Climatic Zone
}

\author{
Crosby $\mathrm{P}^{1}$, Basil .T. Kochupurackal ${ }^{2}$, Dr. S. Rajkumar ${ }^{3}$ \\ ${ }^{1}$ Assistant Engineering Manager, L\&T Construction, India, Email: crosby @1ntecc.com \\ ${ }^{2}$ Assistant Engineering Manager, L\&T Construction, India, Email: basil@lntecc.com \\ ${ }^{3}$ Deputy General Manager, L\&T Construction, India, Email: energyraj@1ntecc.com
}

\begin{abstract}
Building sector continues to grow into one of the biggest consumers of energy in south Asian countries (classified majorly as very hot-humid and dry climatic zone). Estimates account space air-conditioning at nearly 50\% of the energy consumption in commercial building sector, making energy a significant operational cost. Evolution of energy efficient space cooling system thus becomes a prerogative criteria (since the CDD10 is greater than 5000), paving the way for localized/personalized cooling. The research involves analysis of energy consumption patterns for a typical office space with a) Variable air volume system, b) Radiant floor cooling system c) Localized cooling by radiant panels on workstations. For the respective systems, zone cooling set point temperatures is varied based on climate responsive standard of India (representative of south Asian climate zone) and ASHRAE standard as baseline to arrive at the prospective cooling energy consumption patterns. Definitive deviance potential from the baseline present an opportunity to adopt energy efficient strategies. Greater impetus is provided to personalize cooling since from an energy consumption perspective, it reduces energy consumption by $30 \%$ over VAV system. Furthermore, tabs are kept on air distribution pattern and quality of air in the conditioned office space (by considering the standard $\mathrm{k}-\mathcal{E}$ turbulence model) ensuring human comfort has greater degree of significance to energy consumption optimization.
\end{abstract}

\section{Introduction}

Globally, building construction and occupation have come under spotlight for its very strong linkages with energy use and climate impacts. Efficient use of energy is strongly emphasized over the last decade or so, since the reserve of our global energy resources is finite and depleting. The World Energy Outlook 2009, the global energy usage tracker of the Paris-based International Energy Agency says that the half of world's population in cities is already consuming two-third of world's energy. By 2030, cities will be consuming 73 per cent of world energy, accounting for 70 per cent of $\mathrm{CO} 2$ emissions. It projects big increase in energy and global $\mathrm{CO} 2$ from the increase in floor space in buildings of various types, especially in non-OECD countries (Organization of Economic Cooperation of Developed Countries) due to lifestyle changes. Within the climate and energy debate the urban consumption pattern in building units in cities thus becomes the focal point of mitigation.

A study by IPCC 1996 indicates, share of energy consumption by residential, commercial and institutional building sector across the globe is expected at $38 \%$ by 2050. This increase is directly a result of rapid urbanization and growth of cities as major economic hubs in developing countries. Indian Green Building council says the global growth rate of construction Industry is $5.2 \%$ and specific to India, the figure nearly doubles to 10\%. According to Energy Statistics 2013 of India's National Statistical Organization (NSO) shows electricity accounted for more than 57 per cent of the total energy consumption during 2011-12 in India, and building sector is already consuming close to 40 per cent of the electricity. This is expected to increase to 76 per cent by 2040 . With the rapid increase in urbanization and its associated energy usage, there exists a massive demand to provide energy optimization solution for building operation.

Within a building, nearly $20 \%$ of the total energy demand is consumed as operational energy. Optimizing the operational energy demand in a positive way will influence the overall energy requirements of the building industry. Commercial offices offers a vivid opportunity to install/retrofit energy efficiency measures to optimize operational energy. Many research has benchmarked heating, ventilation and air-conditioning as the major energy guzzler in commercial office spaces with estimates at around 50 to $60 \%$ of overall energy consumed by building. Despite perceptions to the contrary, energyefficient offices are not expensive, difficult to manage or inflexible. Nor are they low on comfort and productivity. Energy-efficient techniques which work well tend to be reliable, straightforward, and compatible with management and user needs. Capital costs are often similar to those for normal offices, although budgets may be spent differently - for example, on measures to decrease cooling loads instead of on air-conditioning. Radiant cooling system and personalized radiant panel systems are few of such technology which is impending in India.

Radiant cooling systems provide an opportunity to achieve significant energy and peak demand savings compared to conventional HVAC systems. Radiant cooling systems have circulation of water in pipes or tubes embedded in floor or ceiling or even on other surfaces such as walls. With radiant systems, people are cooled by radiant heat transfer from their bodies to adjacent 
surfaces - ceilings, walls, or floors - whose temperatures are held a few degrees cooler than ambient. This produces higher savings, since water has more than 3400 times the energy transport capacity of air. Since radiant cooling can take care of only sensible loads, parallel schemes are required for latent loads. These methods may form part of the ventilation strategy such as dedicated outdoor air systems.

Even though the radiant cooling system is comfortable and energy saving, application of the same is limited by the condensation problem that might happen. Condensation occurs when the surface temperature of the panels is lower than the dew point temperature of room air. And the sudden increasing of moisture gain indoors or the decreasing of supply water to improve cooling capacity cause condensation (Wufen Jin et al.2015) This will directly affect the efficiency of the chiller and the operating conditions of cooling system. In order to avoid condensation, the surface temperature of panels should be controlled higher than the dew point temperature, which will limit the cooling capacity. Radiant systems are able to provide better and more uniform thermal environment [Olesen 2008], since the mean radiant temperature is also an important factor which affects the comfort of people. Various other benefits of radiant cooling system includes greater architecture flexibility, reduced operating and maintenance costs and more effective control of ventilation [Uponor].

The major function of an air conditioning system is to make people feel comfortable even during adverse outside conditions. In an office environment most of the time individual will be in his seat and working. By using radiant panels in the workstation, we tried to make the conditioning more localised so that the individual will feel more comfortable while working. So the amount of air to be treated will be drastically reduced which will directly affect the savings without any effect on the comfort of the people inside. The remaining area in the room was supplied with the fresh air by separate AHU's specified as per the standards and hence the ventilation was also taken care of. In this research, we found out the energy saving comparison of a radiant ceiling cooling system and localized cooling with radiant panels on workstation with a conventional VAV system designed as per ASHRAE standard. This paper will definitely help as a basis for future researches in the radiant cooling areas for the designing of an energy efficient building.

\section{Methodology}

To provide thermally comfortable environment, conditioning the built space becomes a prerogative in hothumid and dry climatic zone. Upholding the thermal comfort index at acceptable levels offers a challenge to optimized building operational energy consumption.
With this in hindsight, the study utilizes whole building energy simulation approach to analyze energy consumption patterns of three different zone air-

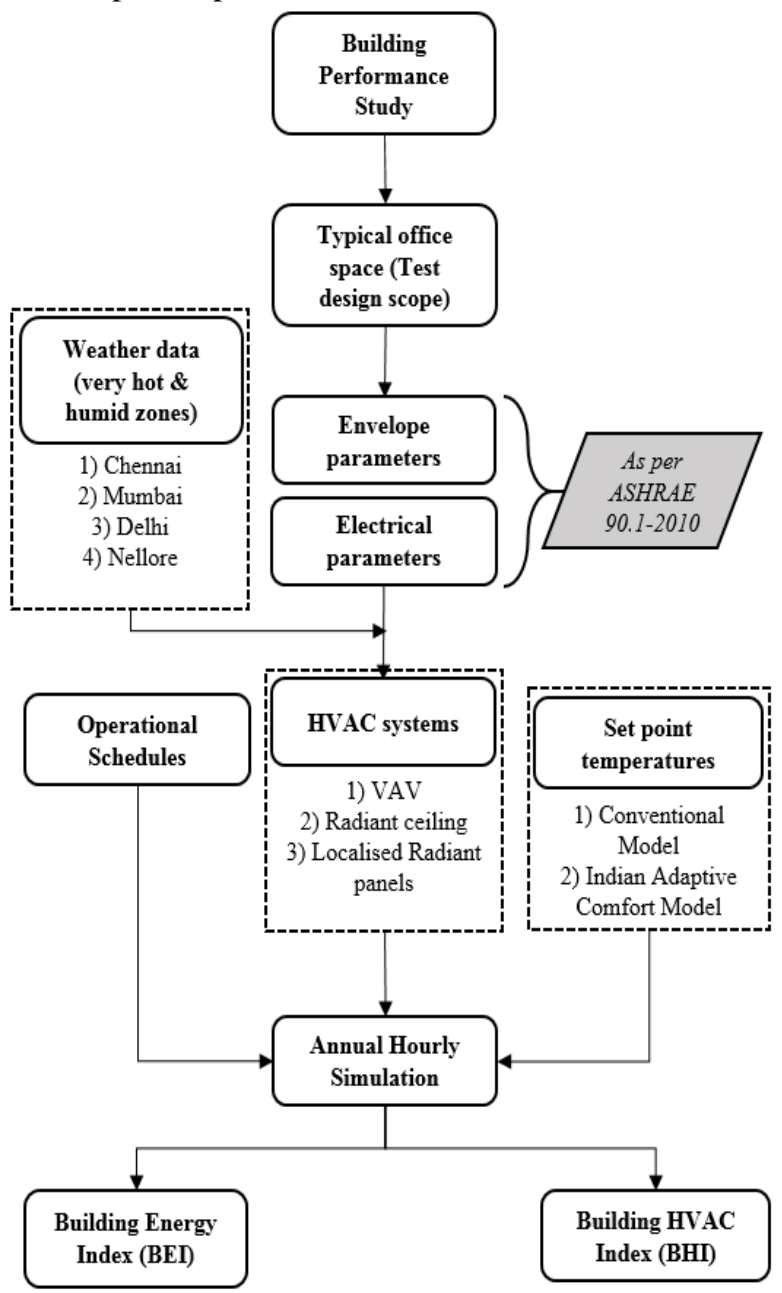

Figure 1: Study Methodology

conditioning systems for a typical office space. The HVAC systems considered for comparison on the basis of comparable first costs are a) Variable air volume system, b) Radiant ceiling system and c) Personalized radiant panel system. The HVAC systems cater to the cooling demand of a 12 floor typical office layout with an overall built up area of about $7500 \mathrm{~m}^{2}$. Figure 1 details the methodology adopted for study. ASHRAE 90.1-2010 is considered as basis for occupancy, envelope, lighting power density, equipment power density and associated operational schedules. The exact values are referenced in Table 1

Zone air set point temperature is also varied to determine the degree of energy optimization potential. Conventional model with a set point of $24^{\circ} \mathrm{C}$ and set back of $26^{\circ} \mathrm{C}$ and Indian Adaptive model with a climate responsive set point temperatures graphed in Figure 6 and a setback of $+1.5^{\circ} \mathrm{C}$ from set point are considered as the basis of HVAC system sizing. 
Table 1: Building Simulation Inputs - As per ASHRAE 90.1-2010

\begin{tabular}{|c|c|c|c|}
\hline S. No & Description & Value & Unit \\
\hline 1 & Occupant density & 0.05 & people $/ \mathrm{m}^{2}$ \\
\hline 2 & Roof assembly U value & 0.36 & $\mathrm{~W} / \mathrm{m}^{2} .{ }^{\circ} \mathrm{K}$ \\
\hline 3 & Wall assembly U value & 0.70 & $\mathrm{~W} / \mathrm{m}^{2} .{ }^{\circ} \mathrm{K}$ \\
\hline 4 & Window to Wall ratio & 40.00 & $\%$ \\
\hline 5 & Glazing U value & 6.81 & $\mathrm{~W} / \mathrm{m}^{2} .{ }^{\circ} \mathrm{K}$ \\
\hline 6 & Glazing SHGC & 0.25 & No unit \\
\hline 7 & $\begin{array}{c}\text { Equipment Power } \\
\text { density }\end{array}$ & 0.75 & $\mathrm{~W} / \mathrm{m}^{2}$ \\
\hline 8 & Lighting power density & 0.90 & $\mathrm{~W} / \mathrm{m}^{2}$ \\
\hline
\end{tabular}

To avoid skewedness in the annual hourly simulation results, weather profiles of 4 cities namely Delhi, Chennai, Mumbai and Nellore are considered to normalize the energy consumption patterns.

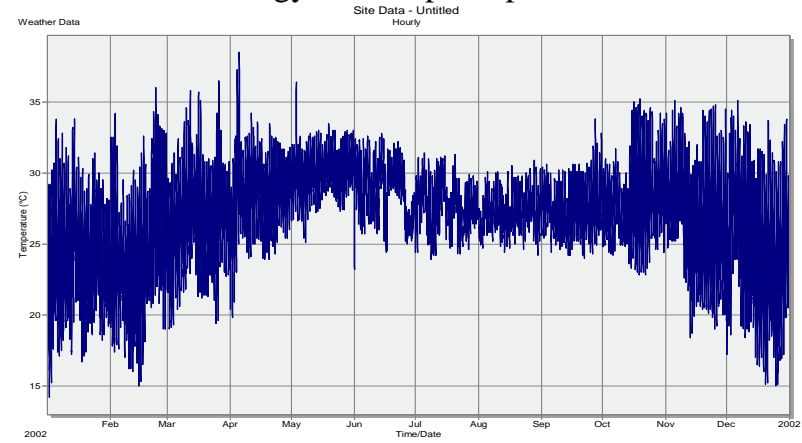

Figure 2: Mumbai DBT (hourly)
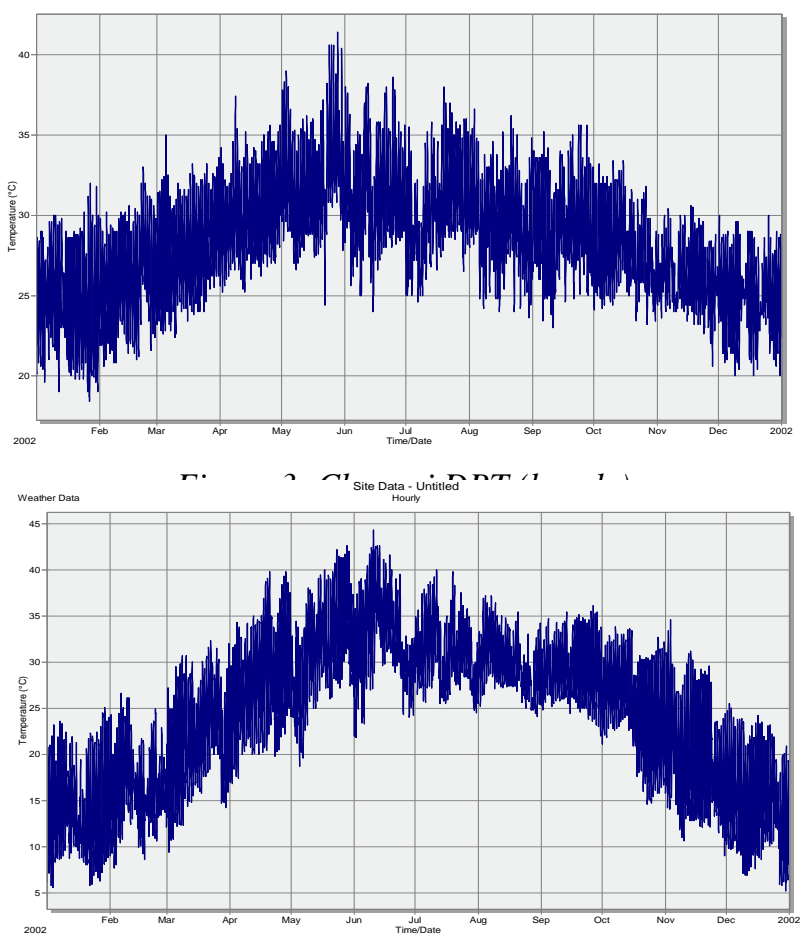

Figure 4: Delhi DBT (hourly)

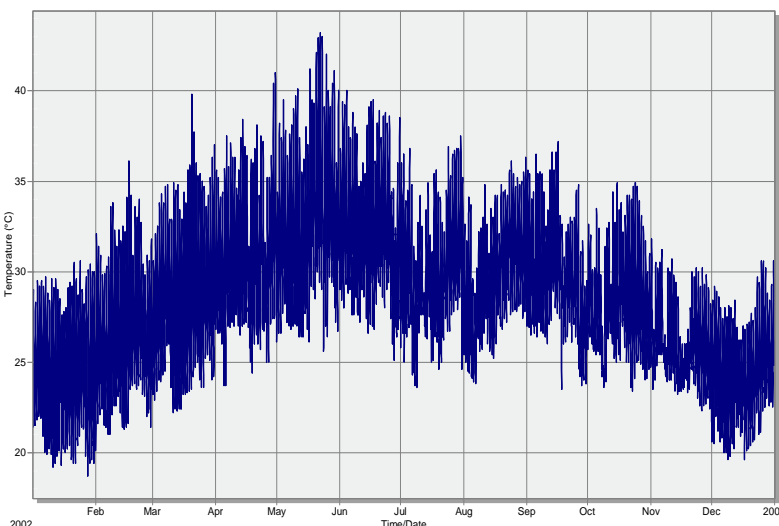

Figure 5: Nellore DBT (hourly)

Figures 2 to 5 capture the hourly ambient dry bulb temperatures (DBT) of the above cities. On the basis of above detailed criteria, Building energy performance index $\left(\mathrm{kWh} / \mathrm{m}^{2}\right)$ and building HVAC performance index $\left(\mathrm{kWh} / \mathrm{m}^{2}\right)$ is evaluated for a typical office space. The climate responsive set point temperatures are calculated using equation 1 , which denotes the relationship between zone operative temperature and ambient dry bulb temperature of location.

$T_{o}=0.078 * T_{a d b t}+23.25$

Where,

$T_{o}:$ Operative temperature

$T_{\text {adbt }}:$ Ambient dry bulb temperature

$90 \%$ acceptability levels $=T_{o} \pm 1.5$

Equation 2 indicates that zone operative air temperature range in which $90 \%$ of office occupants are comfortable. The climate responsive set point temperature is an alternative path to determine thermal sensation in comparison to Predictive Mean Vote (PMV) model.

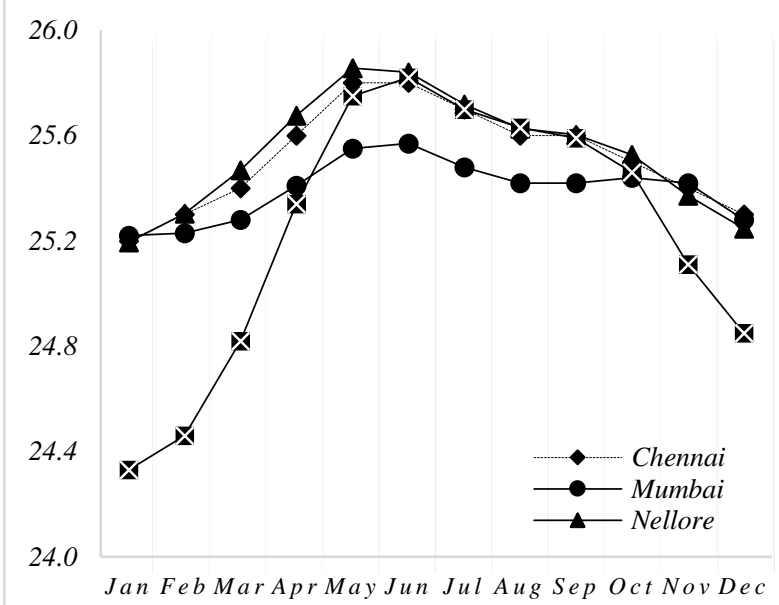

Figure 6: Set point temperature - Indian Adaptive Comfort Model 


\section{Software used}

Annual energy consumption patterns for the three HVAC systems considered for the research study is simulated using DesignBuilder software version 4.7. The capabilities of the software concerning building energy simulation is compliant with ASHRAE standard 140 requirements. DesignBuilder uses EnergyPlus dynamic simulation engine to generate performance data of the buildings like cooling load, energy consumption, monthly demand and so on.

\section{Simulation models}

The study mainly focuses on the energy consumption as a result of various HVAC systems.

\section{a) Variable Air Volume system}

The baseline system considered for analysis is variable air volume system shown in Figure 7 . The supply air

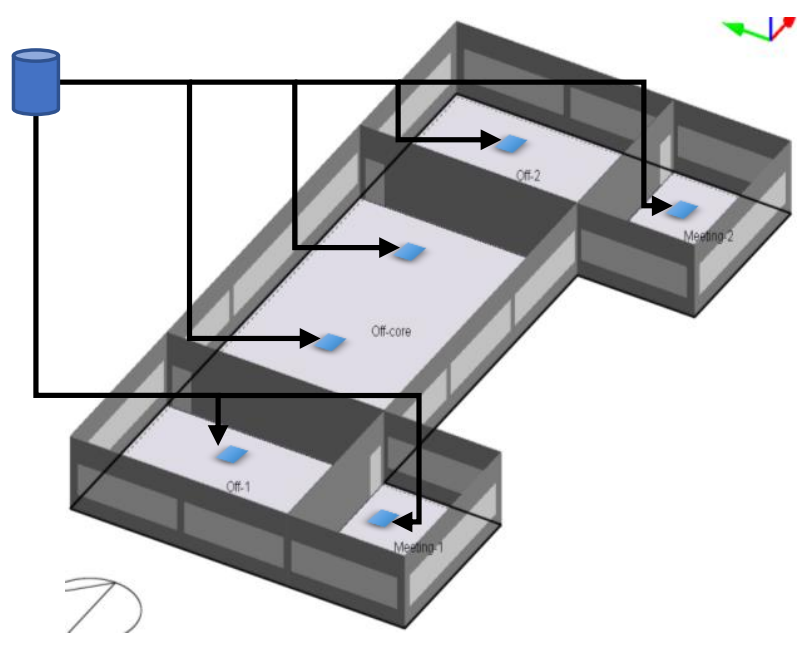

Figure 7: Variable air volume system

(inclusive of fresh air requirements as per ASHRAE 62.12010) to each conditioned zone is catered by a parallel fan powered variable air volume box. All the VAV boxes in a floor are connected to a single air handling unit whose cooling coils are catered by a water cooled chiller sized as per ASHRAE 90.1-2010 recommendations.

Modelling of VAV system is not explained in detail as it is designed and modeled as per ASHRAE 90.1-2010, Appendix G guidelines.

\section{b) Radiant Ceiling System}

With regards to radiant cooling system, the fresh air is still served by the VAV boxes in combination with air handling system. To negate the effects of primarily sensible loads of each zone by conditioning the zone, radiant tubes are laid down in zone ceiling construction.

Radiant ceiling cooling system incorporates chilled ceiling to provide a thermally comfortable environment for occupants. To enable this, chilled water is circulated through in-situ tubes located within ceiling construction, thus reducing the surface radiant temperature. All bodies radiate or absorb heat and the degree of radiant heat transfer is directly proportional to temperature difference between bodies. When the phenomena of heat absorption by zone occupants is higher, the thermal perception shifts to hot as referred from PMV scale. The chilled ceiling improves the thermal perception of occupants to 'neutral' by cooling surrounding surfaces (i.e. ceiling in our case) thereby creating comfortable conditioned zones.

\section{Modelling of radiant ceiling cooling system}

First stage in modelling the radiant ceiling in DesignBuilder software is to switch on the "internal source" option (in ceilings/roof), available in the "constructions" tab. Then in HVAC system modelling the chilled water tubes are modeled inside the zones and is designed so as to meet the sensible load of the zone. After this the chilled water tubes from all the zones are

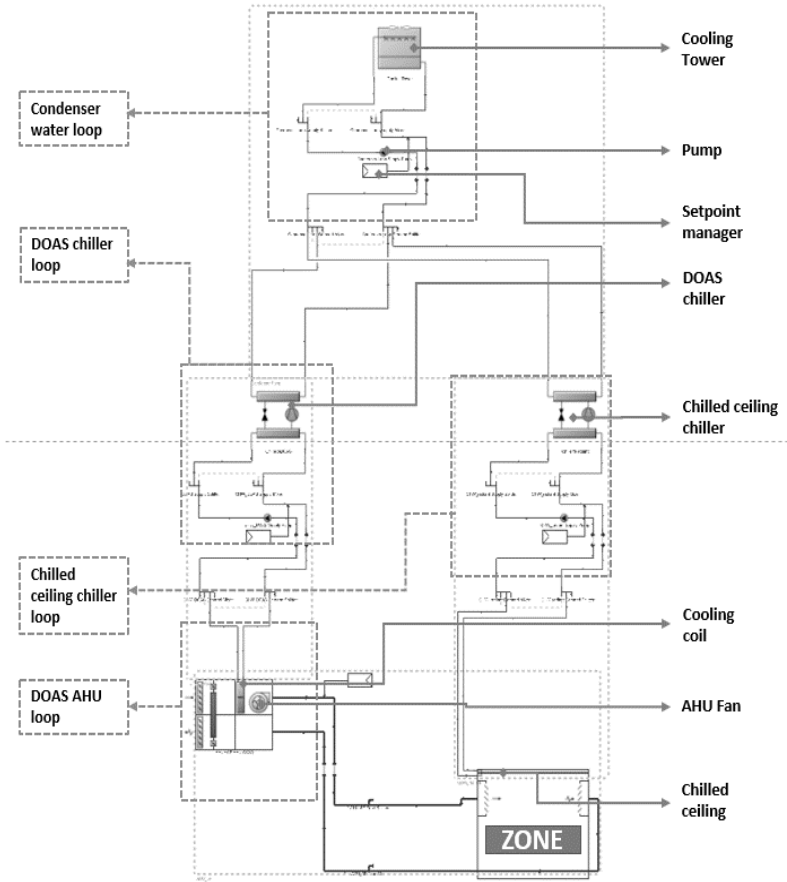

Figure 8: Radiant ceiling system - Model

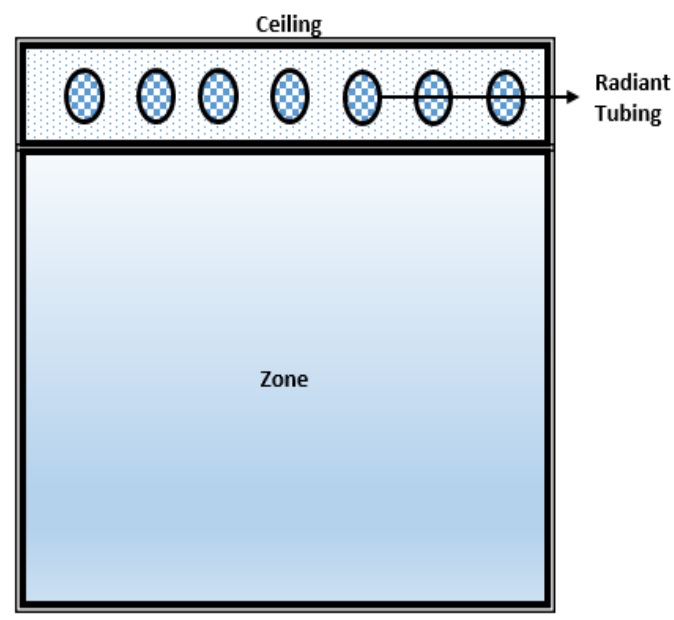

Figure 9: Radiant ceiling - cross section

connected to a separate chiller designed separately for radiant cooling ceiling system. Here the radiant tubes are designed to run throughout the ceiling area of each level, 
which is around $660 \mathrm{~m}^{2}$ per level. Figure 8 indicates the schematic diagram of radiant cooling system modelled in design builder and Figure 9 provides a cross section of tubes in zone.

The desired temperature difference between circulating chilled water and conditioned zone temperature is only $3-$ $5^{\circ} \mathrm{C}$ (i.e. the circulating water temperature is supplied at $18-20{ }^{\circ} \mathrm{C}$ ). Water, with its inherent higher specific heat capacity, absorbs heat from the conditioned zone and follows the stages on refrigeration cycle. Majority of sensible heat will be removed by this process and the remaining loads (mostly latent loads) is catered by independent Direct Outdoor Air (DOAS) system (Figure 9). High cooling capacity of water in combination with higher chilled water temperature inadvertently ensures energy consumption savings is higher when compared with conventional HVAC systems.

\section{c) Personalized Cooling System}

Personalized cooling also captures the essence of radiant cooling system for space conditioning. The primary difference is that personalized cooling contains radiant panels in workstation area thereby.

The benefit here is, only workstation area is cooled to set point temperature (refer Figure 6) by radiant panels in which chilled water is circulated. Whereas the other circulation zones along with ventilation loads are catered by DOAS system to ensure comfort conditioning. Therefore, the purpose of personalized cooling is to limit the requirement of cooling to precise set points within the zone volume that are predominantly occupied (i.e. the occupant microclimate) by occupied for maximum hours.

\section{Modelling of personalized radiant panel system}

Similar to radiant ceiling cooling the personalized cooling panels were also modeled in the software with the only difference being the radiant panels were modeled in the zone only above the cubicles of occupants. This reduces the tube length of chilled water and making the

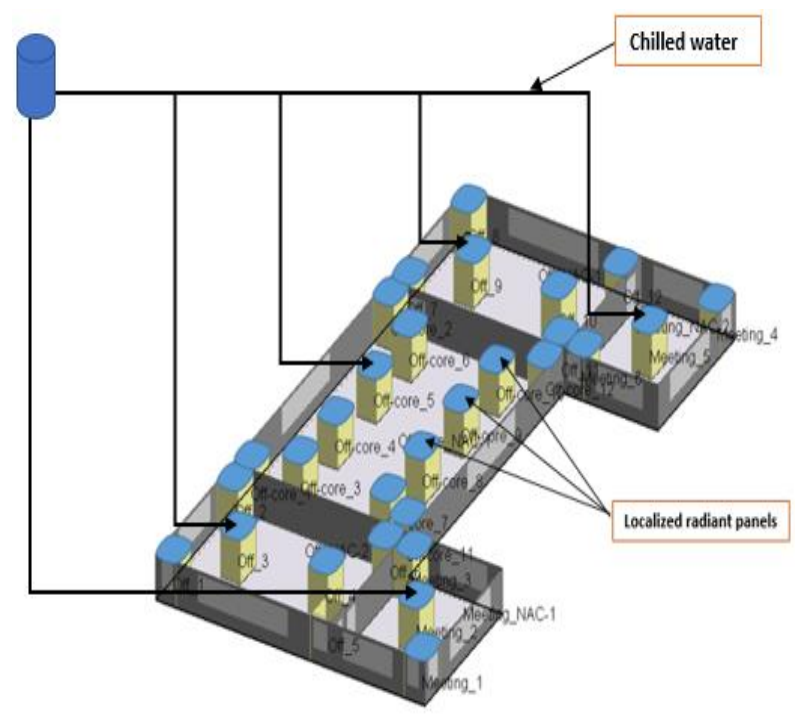

Figure 10: Personalized cooling conditioning personalized. All the radiant panels are then connected to chiller specifically for this panels and the chilled water is passed through the tubes based on the cooling load. In this case the number of occupants per floor area is considered as per ASHRAE standards and based on that each cubicle area is determined. Total cubicle ceiling area per level comes around $90 \mathrm{~m}^{2}$ and only in this area the radiant panels are modeled and in other areas the AHU will be supplying cooled air so as the setpoint air temperature is met (2 degree higher than cubicle area for ASHRAE case and 1.5 degree higher for adaptive comfort case). Schematic of the personalized cooling modeled in Designbuilder software is shown in Figure 10

\section{Discussion and results}

The simulations for the three different systems were carried out in Design Builder version 4.7.0.027. All simulations have been carried out for 8760 hours using the Energyplus engine version 8.3.

\section{a) Analysis of zone set point temperatures}

It is important to ensure rationality on the selection of zone set point temperature as it impacts energy consumption and thermal comfort on equal footing. In this study by considering 4 cities representative of hot-humid and dry climate zones, cooling load and operational energy for conventional set point of $24^{\circ} \mathrm{C}$ and adaptive set point (Figure 6) is analyzed.

Figures 11-13 are representative of energy consumption for 4 major cities considered for analysis. It can be seen, only by adopting a climate responsive set point temperature (i.e. Indian Adaptive Comfort Model in this case), considerable savings in energy consumption is achieved $(5 \%$ in the case of VAV and radiant ceiling system and $3 \%$ in the case of personalized cooling system) independent of the type of air-conditioning system.

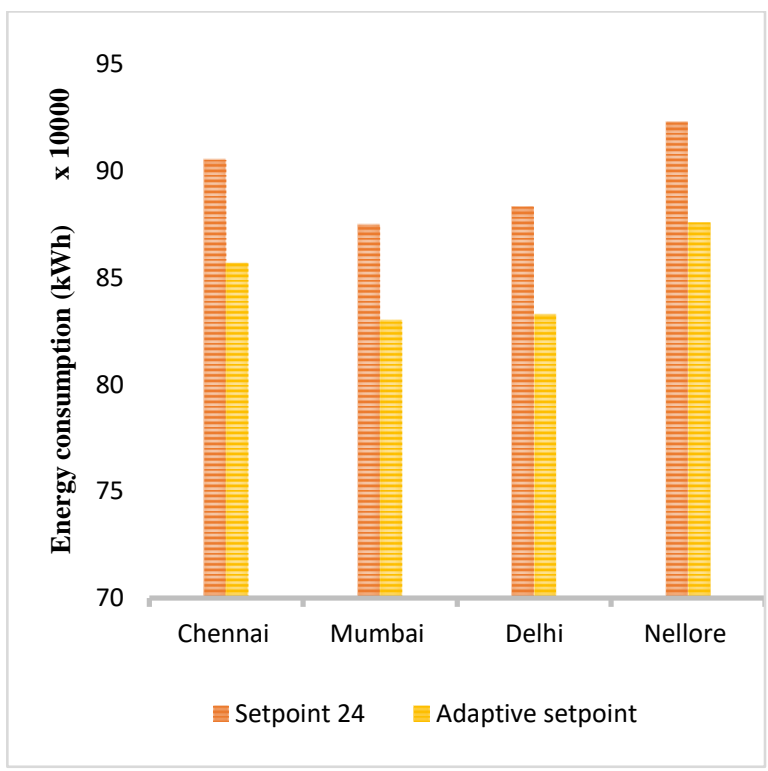

Figure 11: Energy consumption - VAV system 


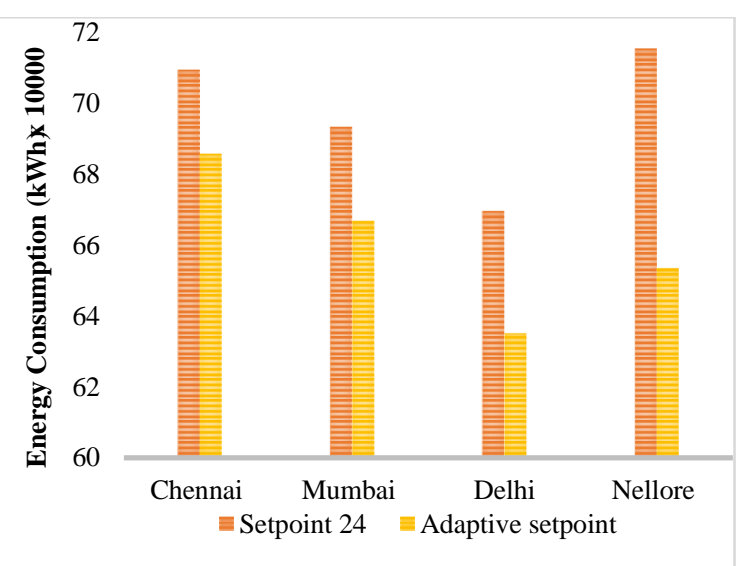

Figure 12: Energy consumption - Radiant ceiling

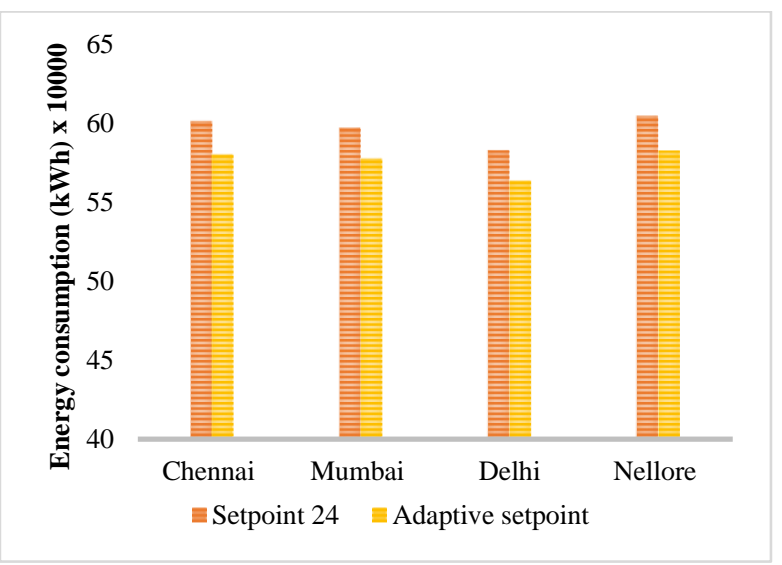

Figure 13: Energy consumption - Personalized cooling

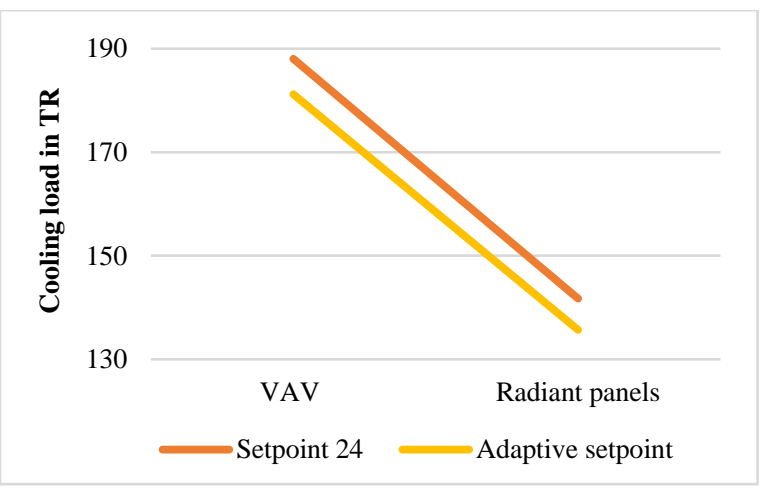

Figure 14: Cooling load comparison

Figure 14 is representative of the cooling load reduction in Tonnage of refrigeration between VAV/Radiant ceilings and personalized cooling systems. Cooling load analysis indicates, adopting adaptive set point temperature $3-4 \%$ reduction in cooling load is achieved.

\section{b) Analysis of Building Performance Index}

In this study, the building performance index is accounted by two dynamics a) Building energy index (BEI) and b) Building HVAC index (BHI).

\section{i) Building Energy Index}

Building energy index $=\frac{\text { operational energy }(k W h)}{\text { Built-up area }\left(m^{2}\right)}$

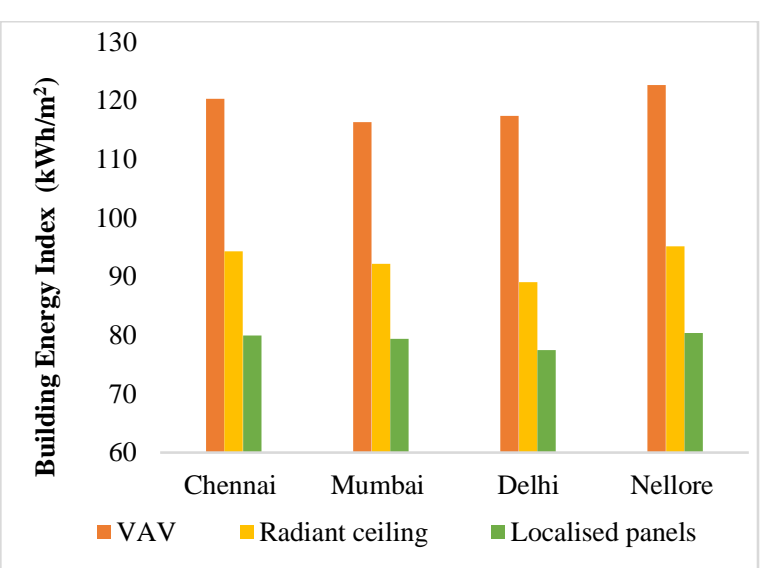

Figure 15: BEI - set point $24^{\circ} \mathrm{C}$

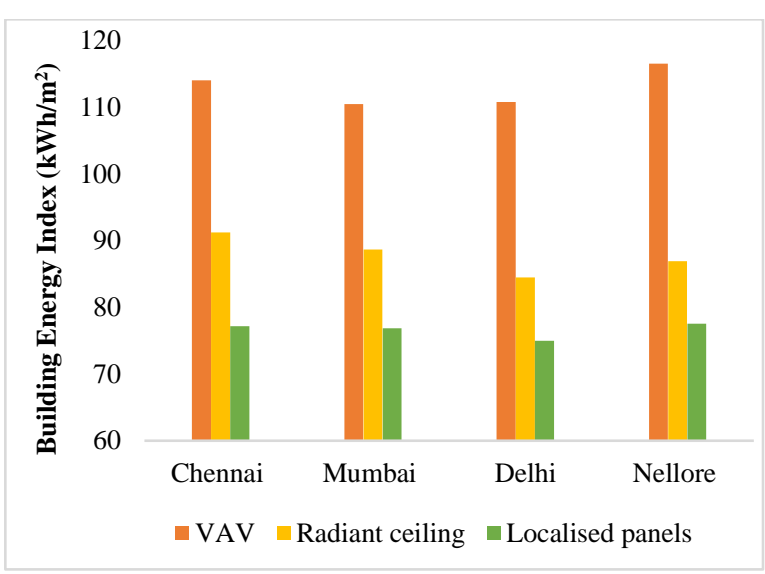

Figure 16: BEI - Adaptive set point

Figure 15 and 16 indicates the building energy index/year for 4 major cities simulated for set point $24^{\circ} \mathrm{C}$ and adaptive set point respectively. VAV system is considered as the baseline for both cases. The savings percentage in terms of BEI is seen in Table 2. It is observed that the BEI reduces from $120 \mathrm{kWh} / \mathrm{m}^{2}$ for VAV system to $80 \mathrm{kWh} / \mathrm{m}^{2}$ in the instance of personalized cooling for case 1 (i.e. conventional set point of $24^{\circ} \mathrm{C}$ ) and for case 2 (i.e. Adaptive comfort model), the BEI reduces from 113 $\mathrm{kW} / \mathrm{m}^{2}$ for VAV to $77 \mathrm{kWh} / \mathrm{m}^{2}$ for personalized cooling system Figure 17.

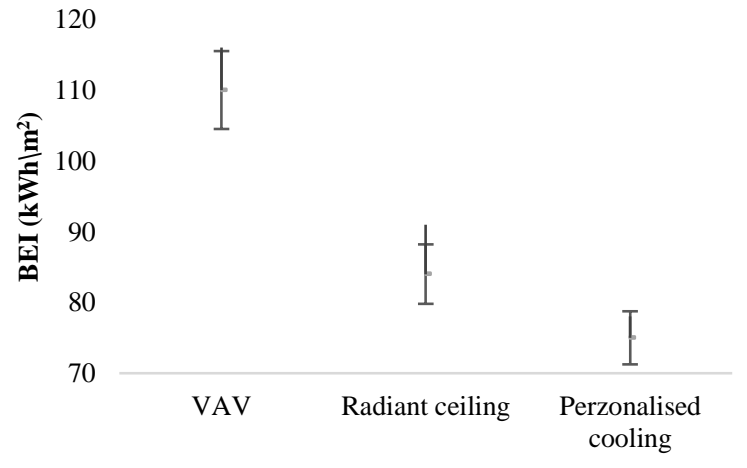

Figure 17: Range of BEI - major cities 
Table 2: BEI - Savings (\%)

\begin{tabular}{|c|c|c|}
\hline System & $\begin{array}{c}\text { Case - 1 } \\
\text { (set point 24 }\end{array}$ & $\begin{array}{c}\text { Case - 2 } \\
\text { Cdaptive set } \\
\text { point) }\end{array}$ \\
\hline VAV & Baseline & Baseline \\
\hline Radiant ceiling & $20-25 \%$ & $19-25 \%$ \\
\hline $\begin{array}{c}\text { Personalized } \\
\text { cooling }\end{array}$ & $33-35 \%$ & $31-34 \%$ \\
\hline
\end{tabular}

In all the three systems compared, the room temperature is $24^{\circ} \mathrm{C}$ for case- 1 . Reasons for energy savings in radiant cooling system is mainly because of the larger thermal mass cooling, the peak load is lowered and also because of the lower energy required to pump chilled water in radiant tubes than distributing cooled air with fans. In personalized cooling the total area to be cooled to $24^{\circ} \mathrm{C}$ itself got reduced (only cubicle areas), as the rest of the area is maintained at 2 degree higher $\left(26^{\circ} \mathrm{C}\right)$, as most of the time occupant is present in cubicle area only. This resulted in more savings than normal radiant ceiling system.

Similarly in case-2 (adaptive setpoint), the setpoint temperature is varying between 24.4 to $25.8^{\circ} \mathrm{C}$ based on the Indian adaptive comfort for each month with a setback of $1.5^{\circ} \mathrm{C}$ for $90 \%$ acceptability limit. This resulted in increasing the inside setpoint by around $1.3^{\circ} \mathrm{C}$ for Indian climates than ASHRAE case, which resulted in more reduction in energy consumption and thereby increasing the savings.

\section{ii) Building HVAC Index}

Building HVAC index (BHI) excludes the lighting and equipment energies from building energy index.

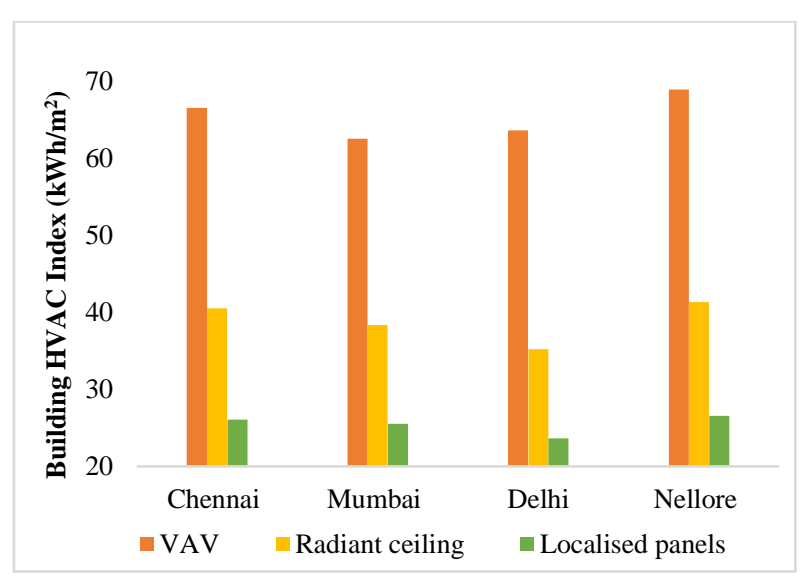

Figure 18: $\mathrm{BHI}$ - set point $24^{\circ} \mathrm{C}$

The energy consumption for lighting and equipment's are $194 \mathrm{MWh} /$ year and $211 \mathrm{MWh} /$ year respectively. BHI enables to quantify actual reduction in energy consumption for space conditioning.
Figure 18 and 19 indicates the building HVAC index/year for 4 major cities simulated for set point $24^{\circ} \mathrm{C}$ and adaptive set point respectively. The savings percentage in terms of BHI is seen in Table 3. It is observed that the BHI reduces from $67 \mathrm{kWh} / \mathrm{m}^{2}$ for baseline VAV system to 26 $\mathrm{kWh} / \mathrm{m}^{2}$ in the instance of personalized cooling for case 1 (i.e. conventional set point of $24^{\circ} \mathrm{C}$ ) and for case 2 (i.e. Adaptive comfort model), the BEI reduces from 60 $\mathrm{kW} / \mathrm{m}^{2}$ for VAV to $23 \mathrm{kWh} / \mathrm{m}^{2}$ for personalized cooling system.

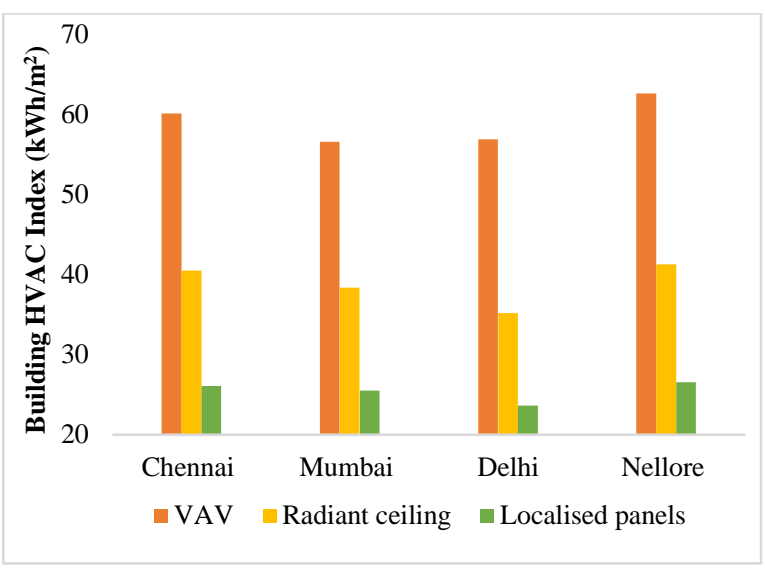

Figure 19: BHI - Adaptive set point

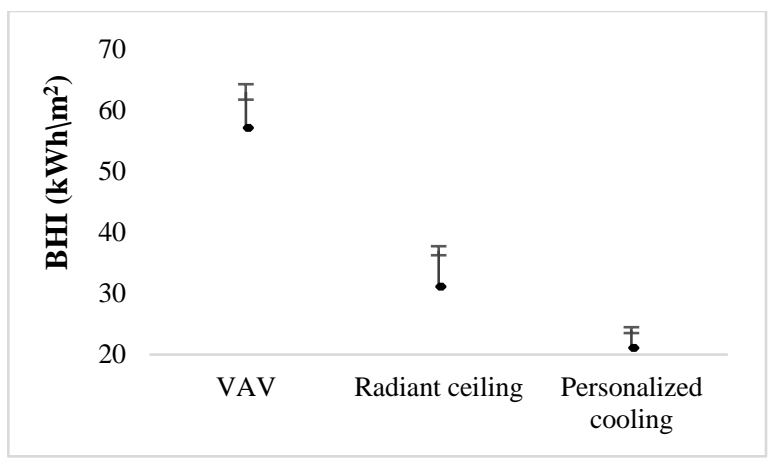

Figure 20: Range of BHI - major cities

This means, with further optimization in lighting and equipment energy the overall building energy index savings will further increase from $31-35 \%$ as indicated in Table 3.

Table 3: BHI - Savings (\%)

\begin{tabular}{|c|c|c|}
\hline System & $\begin{array}{c}\text { Case - 1 } \\
\text { (set point 24 }\end{array}$ & $\begin{array}{c}\text { Case - 2 } \\
\text { (Adaptive set } \\
\text { point) }\end{array}$ \\
\hline VAV & Baseline & Baseline \\
\hline Radiant ceiling & $37-46 \%$ & $37-48 \%$ \\
\hline $\begin{array}{c}\text { Personalized } \\
\text { cooling }\end{array}$ & $59-64 \%$ & $60-64 \%$ \\
\hline
\end{tabular}

\section{c) Analysis of surface temperatures for condensation:}

One of the major drawbacks with the Radiant cooling system is condensation. When temperature of panel is below dew point temperature of room air, then the 
moisture present in the air condenses. This will result into microbial growth which decreases the air quality. (Fred S. Bauman et.al., 1996). It has been shown that with the use of personalized cooling system, thermal comfort can be well maintained even at the room air temperatures reaching $30^{\circ} \mathrm{C}$ and at a relative humidity of $60-70 \%$ (Zhai $\mathrm{Y}$ et.al, 2013).

In this study, the surface temperature variation is analyzed against zone dew point temperature during hottest months (i.e. from May to August) to identify the possibility of condensation. Figure 21- 24 represents the temperature variation for the major cities under consideration.

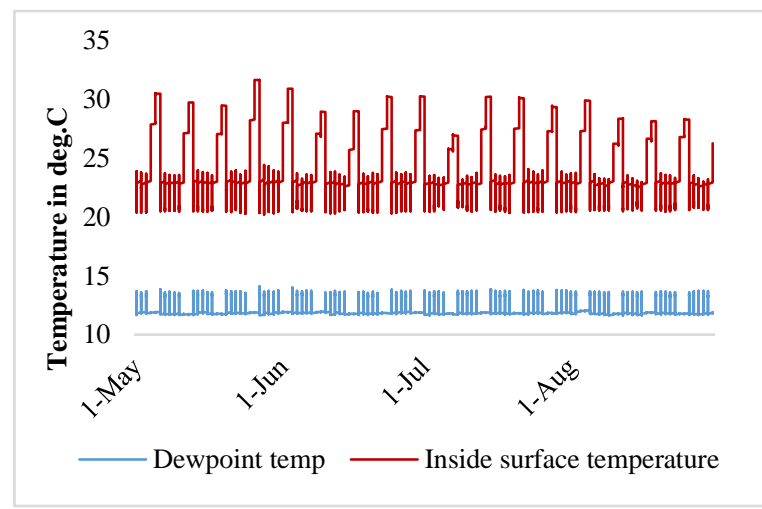

Figure 21: Dew point and surface temperature variation - Chennai

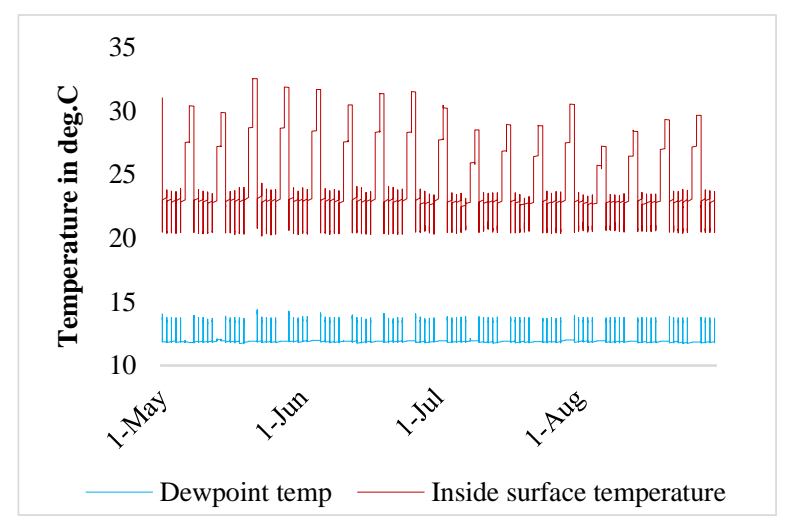

Figure 22: Dew point and surface temperature variation - Nellore

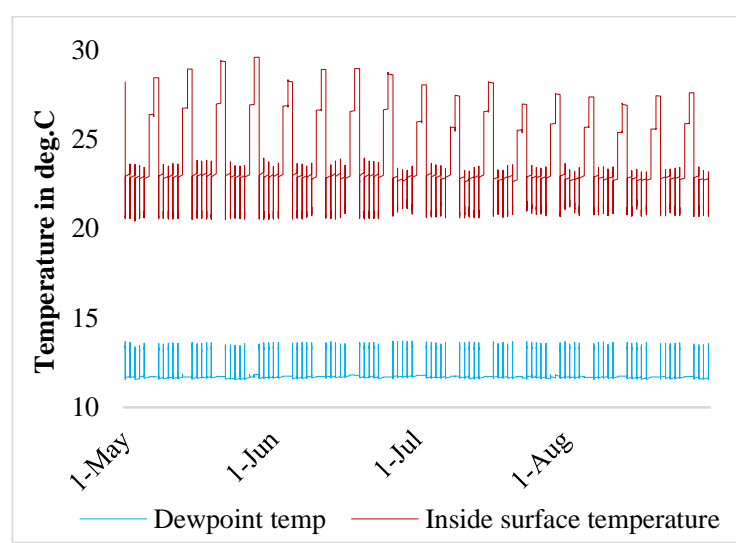

Figure 23: Dew point and surface temperature variation - Mumbai

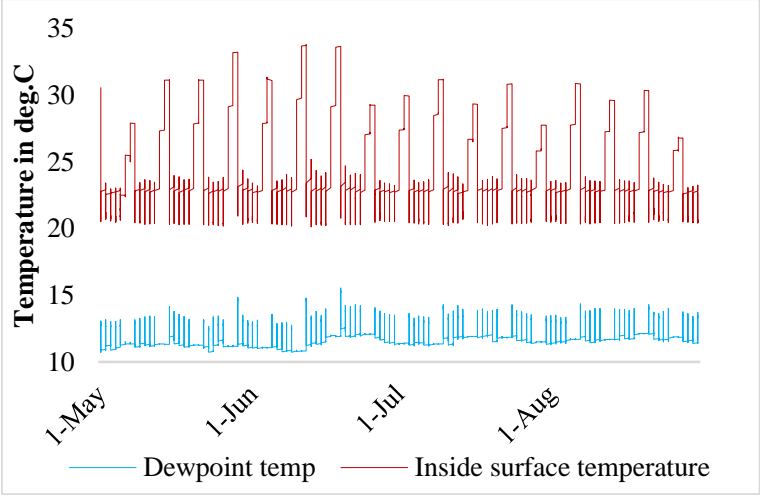

Figure 24: Dew point and surface temperature variation - Delhi

The surface temperature is analyzed for personalized cooling where the possibility of condensation is higher. With the chilled water temperature circulating inside the radiant tubes maintained at 18 to $20^{\circ} \mathrm{C}$ during typical office hours, the extent of condensation to affect thermal perception of occupants is non-existent.

\section{Conclusion}

Based on the simulation results, radiant cooling and personalized cooling potentially redefines the way cooling is done for typical office spaces. The following broad points are observed which adds values to more wide adoption of personalized cooling.

- Personalized cooling is less complex in terms of number, size and space requirement of equipment's on high side and low side than conventional systems.

- With regards to building performance index, conservatively 46 to $48 \%$ energy savings can be achieved which when translated to building operational cost results in huge monetary savings.

- The condensation phenomena which goes against the implementation of personalized cooling is virtually non-existent to affect occupant thermal comfort.

\section{References}

B. W. Olesen, "Radiant floor cooling systems," ASHRAE Journal, Bd. 50, Nr. 9, pp. 16-22, 2008

Fred S. Bauman and Edward A. Arens, Task/Ambient Conditioning Systems: Engineering and Application Guidelines by CEDR, University of California, Berkeley, October 1996.

Radiant cooling research, CBRE, University of California, Berkeley, 2010.

Uponor, Radiant Cooling Design Manual (RCDM) First Edition.

Wufen Jin, Lizhi Jia, Qian Wang, Zhihao Yu, Study on condensation features of radiant cooling ceiling, Procedia Engineering 121 (2015), 1682-1688

Zhai Y, Zhang H, Zhang Y, Pasut W, Arens E,Meng Q. Comfort under personally controlled air movement in warm and humid environments. Build Environ 2013;65:109-17. 